\title{
Overall brand design of elite sports nautical resources - its role and importance in increasing and affirming University reputation
}

\author{
Hristina Vasileva Tacheva \\ Technical University of Varna, Department Industrial Design, 9010, 1 Studentska Street, Varna, Bulgaria \\ Corresponding author contact: hriz@abv.bg
}

\begin{abstract}
Each university affirms its reputation in society not only by its scientific and professional achievements but also by certain PR strategies built with the help of well-selected and graphically designed printed and media-based editions, advert messages and signs on billboards and other devices in the sphere of external advertising. The present study of the opportunities offered by nautical sports resources for advertising, popularizing and enhancing the university prestige is part of a theme elaborated in a dissertation. It is also part of building an overall PR strategy.
\end{abstract}

Keywords: nautical sports, university prestige, conceptual models, designing signs, regalia

\section{Introduction}

The present study of the opportunities offered by nautical sports resources for advertising, popularizing and enhancing the university prestige is part of a theme elaborated in a dissertation "Developing of a detailed methodology for creating conceptual models while designing signs, symbols and regalia for academic purposes". It is also part of building an overall PR strategy.

Each university affirms its reputation in society not only by its scientific and professional achievements but also by certain PR strategies built with the help of well-selected and graphically designed printed and media-based editions, advert messages and signs on billboards and other devices in the sphere of external advertising. They are based on a specific system of academic symbols and signs that synthesize the advertising strategy of a university. Therefore, overall conceptual models should be designed on a common theoretical basis of symbols. The contemporary tendencies in the sphere of the classic graphic, company, brand design as well as the major terms and notions in this field were already discussed in greater detail in some other publications. (Тачева, 2016, Tacheva, 2017) One of the major conclusions of this research was that the problem with academic identity and PR is extremely important and topical in relation to the contemporary higher education institutions in our country which struggle to affirm their reputation in a complicated and highly dynamic, both national and international competitive environment. Thus, the need for developing of a generic methodology for designing conceptual models for creating signs, symbols and regalia for academic purposes becomes logical and self-evident. 


\section{Discussion}

For several years now at the Medical University of Varna great efforts have been made to create a more precise and aesthetically more recognizable strategy with a potential for future development of an overall designer strategy for company brand design that encompasses products of different genres and design divisions. The updating and enhancing of the logo was the beginning of the creation of a series of rector's regalia gathered around a common idea - necklaces, mace, award plaques, prize fund.

As a result of the overall tendency for modernization and development in 2017 the Academic leadership of MU-Varna decided to increase and improve the opportunities for training programs in sports with some facilities for yachting and sailing. This decision is logical because of the unique location of this academic center, situated in the biggest sea town in Bulgaria with a long tradition of many years of yachting. The elite character of this sport and the media interest in yachting events suggest using varied advertising opportunities that may be encountered. In relation to the common brand conceptual strategy of MU-Varna that has already been constructed and implemented, a task was set to develop and offer projects that meet the following basic criteria.

- To demonstrate belonging, advertise and popularize the activities of MU-Varna;

- The logo and signs of MU-Varna should be clear, and they should allow for quick reading and recognizing, without being crushingly impressive and imbalanced in terms of composition;

- To give opportunities for technical implementation of the project which would ensure durability and endurance in the specific nautical conditions, as well as interchangeability of certain elements;

- Topical and modern design that draws attention, appeals to the students and provokes interest;

- To create a sense of prestige and elitism which would boost students' confidence and enthusiasm in a positive way and would urge and encourage them to take part in sports activities and events;

- $\quad$ Not to require special maintenance and exposure.

The work on the project began with a survey of the basic principles and compositional elements acquired, perceived and accepted in this specific area of design. It is well-known that in our country besides the compulsory and legal requirements for advertising panels and promotional materials and inscriptions on the small freight sailing boats, branding and decorations are not obligatory for all parts of the vessel that allow for such promotional materials. This fact is due mainly to financial reasons and it is easy to explain and understand. Different designer approaches and possible compositional schemes were explored.

At the beginning an analysis was carried out for ranking the most essential and significant elements from the point of view of composition, text and overall visual information that the sailboat must possess - name, registration numbers, logos, colors, address of the webpage. The names of the waterway vessels were carefully chosen to carry a symbolic meaning and relation to Medicine Hygeia and Panacea, the daughters of Asclepius, the major patron and founder of the science of therapy and Thalassa, the primordial goddess of the sea according to the ancient Greek mythology.

Once having been chosen, the names were inscribed in their corresponding logos (Fig. 1). The major goals of this task were to understand basic, sufficiently specific and recognizable colors, simple and elegant style that gives quick and clear information creating associations with the sailing sports, a sense of belonging to the academic community of MU-Varna and unifying compositional elements with common overall style of the separate logos. 


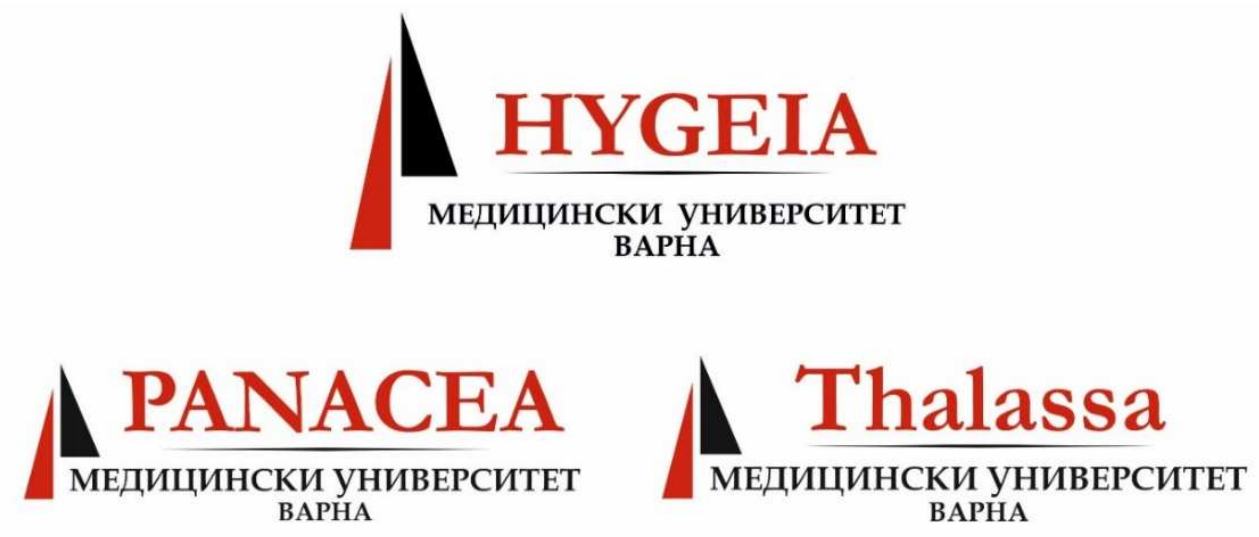

Fig. 1. The sailboat $\log o s^{1}$

Contrasting colors were chosen- red, basic color of the light spectrum, bright, strong, with great emotional charge, individuality and creating moderate contrast with the other color selected black. Both colors are distinctly pronounced on the white hull and sails, standard achromatic production color of the boat. The logos give the main information - the name of the sailboat, the university that the boat belongs to, as well as stylized sails as a basic element in yachting and sailing that puts the finishing touches to the whole composition. The rest of the important information about the boats such as their serial number and identification for the respective harbor were written in an appropriate Sans Serif font for achieving better visual distinction (Лольр, 2006). Here meeting the main requirement should be pointed out because of the variety of objects and places where the respective markings were inscribed or attached later with the help of templates (Fig. 2). Markings were added or applied namely to sails, the hull, team's outfits, protective equipment, such as inflatable life jacket vests, life-saving float rings, etc.
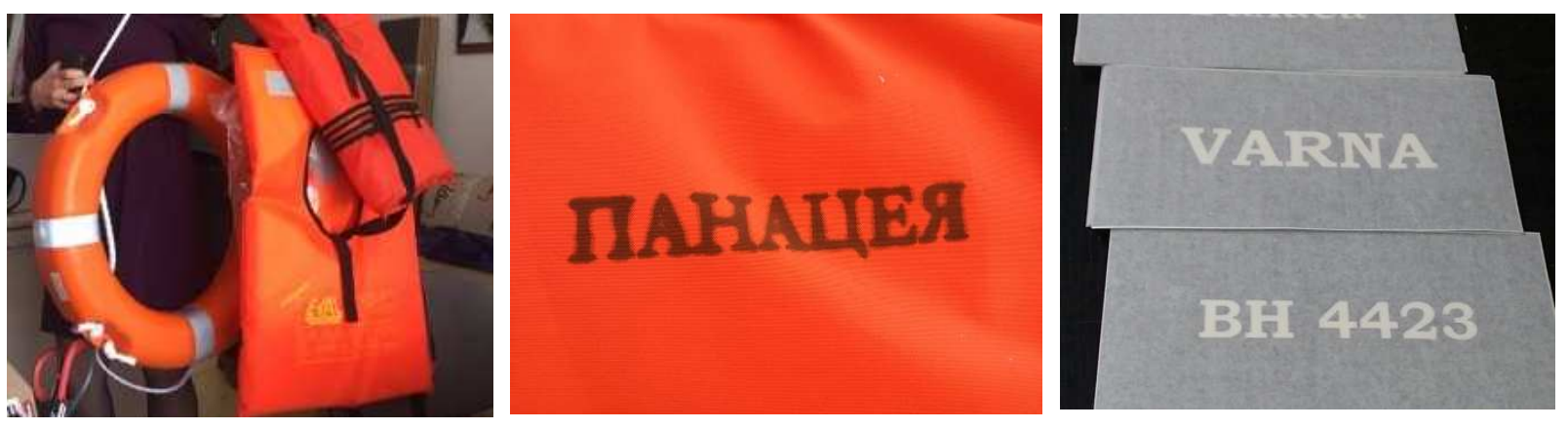

Fig.2. Templates. ${ }^{2}$

On performing the second supervision of the surface areas appropriate for additional information and effective branding, an advertising panel was placed displaying the website of the Medical University of Varna, on the keel and the base of the boat's body part (Fig. 3). Thus, the sign is visible from a great distance and while taking panoramic pictures of the tilting of the yacht in stormy

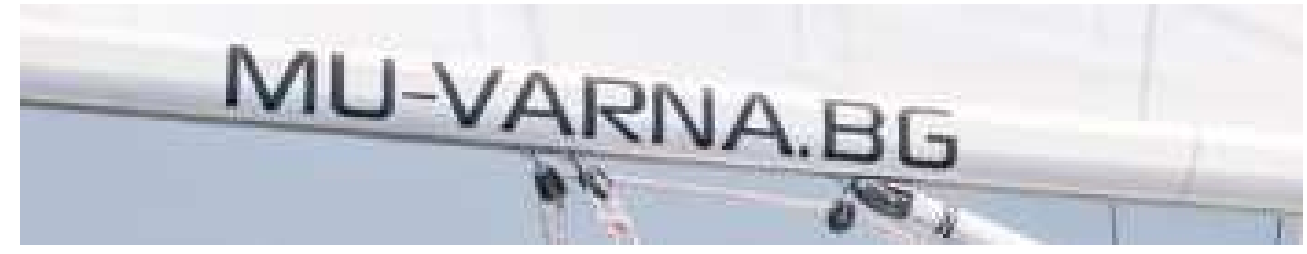

\footnotetext{
${ }^{1}$ The sailboat $\log \operatorname{sos}^{1}$. Personal archive.

${ }^{2}$ Templates. ${ }^{2}$ Personal archive.
} 


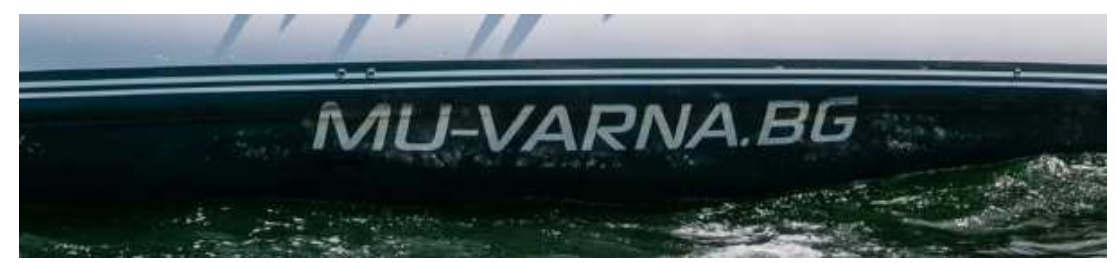

waters.

Fig.3. Advertising panel. ${ }^{3}$

The construction of an overall concept and vision for the major sailing boat Bavaria 46 Cruiser started based on the necessary criteria and after explaining the basic color scheme.

Because of the large visible total area of both the hull and the sails, the project ideas began with the application and combination of many color and graphic elements which had to correspond well to both the chosen name of the boat and its graphic sign on the one hand, and the logo of the Medical University of Varna on the other hand.

Variant 1 (Fig. 4) - In this version the accepted brand colour combination for MU-Varna was blue, grey and white according to the CMYK colour catalogue. The placing of the logo on each sail aims at it being visible at any given time of sailing. Later this variant was rejected because of insufficient contrast and intensity of colour in the elements.

Variant 2(Fig. 4)- this time a much clearer style was presented with big colour "spots" and optimally used branding surface area. As a result, the variant was put aside because of the limited possibility for placing the elements on one side only, insufficient contrast and impossibility for the logo to be complete due to different implementation of the Gennake.
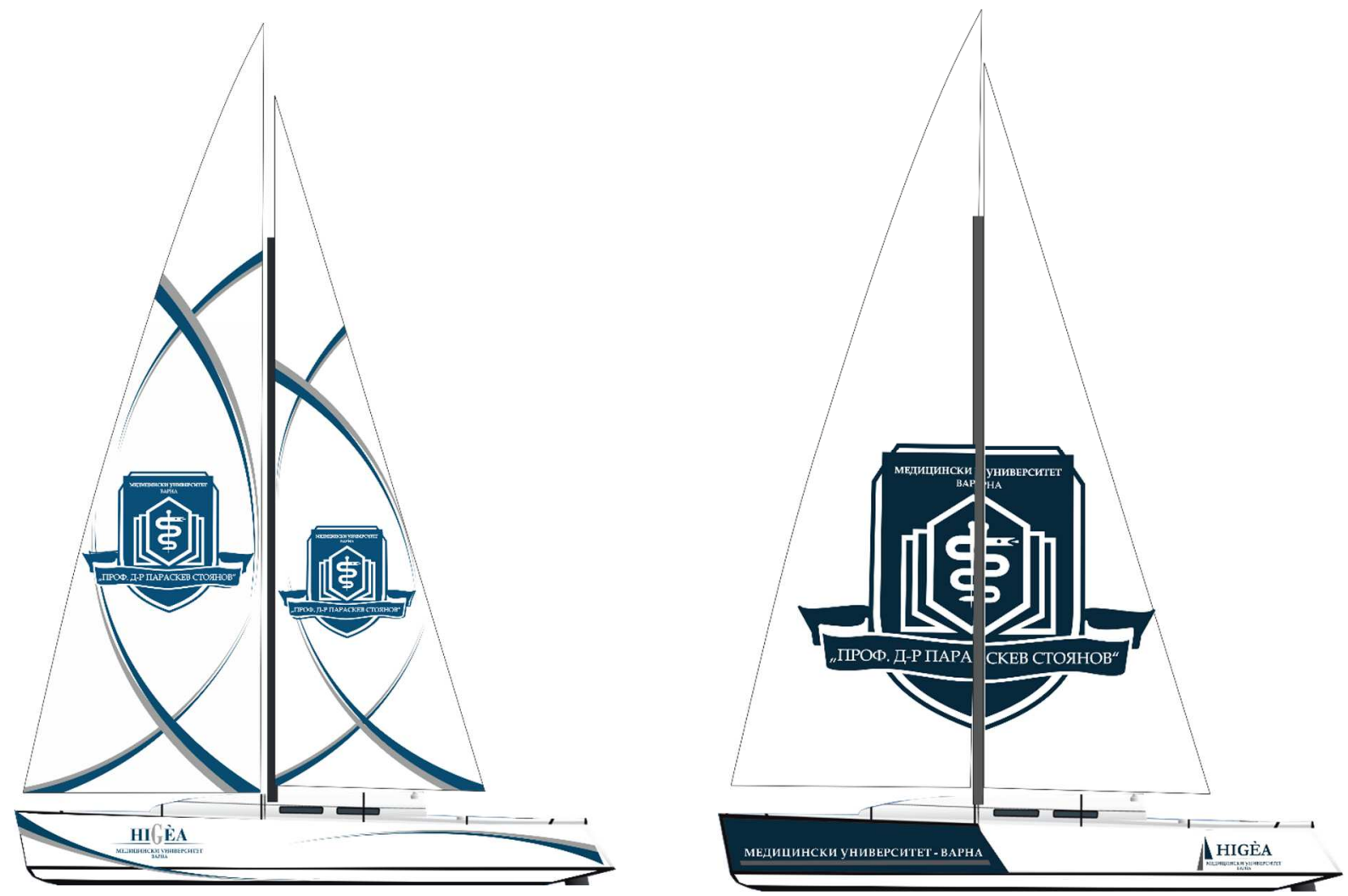

Fig. 4. Variant 1 and $2 .{ }^{4}$

\footnotetext{
${ }^{3}$ Advertising panel. ${ }^{3}$ Personal archive.
} 
Variant 3 (Fig. 5)-presents the emergent idea for an additional contrast while placing straight lines on a larger surface area. However, since the prevailing elements in blue were not distinct enough and tended to merge with the horizon, this variant was also rejected.

Variant 4 (Fig. 5)- This variant meets most of the criteria. Both necessary logos are used and each one of them is placed on a separate sail. The red and black colours introduced, improve the contrast and efficacy of the elements. Some principles of optical decomposition have been applied here. They are based on some disguised patterns following geometrical principles (Тачев, 2015).

Unfortunately, it was established that the surface area of this variant did not allow good enough positioning of the details because of the specific shape of the sails in different wind strength.
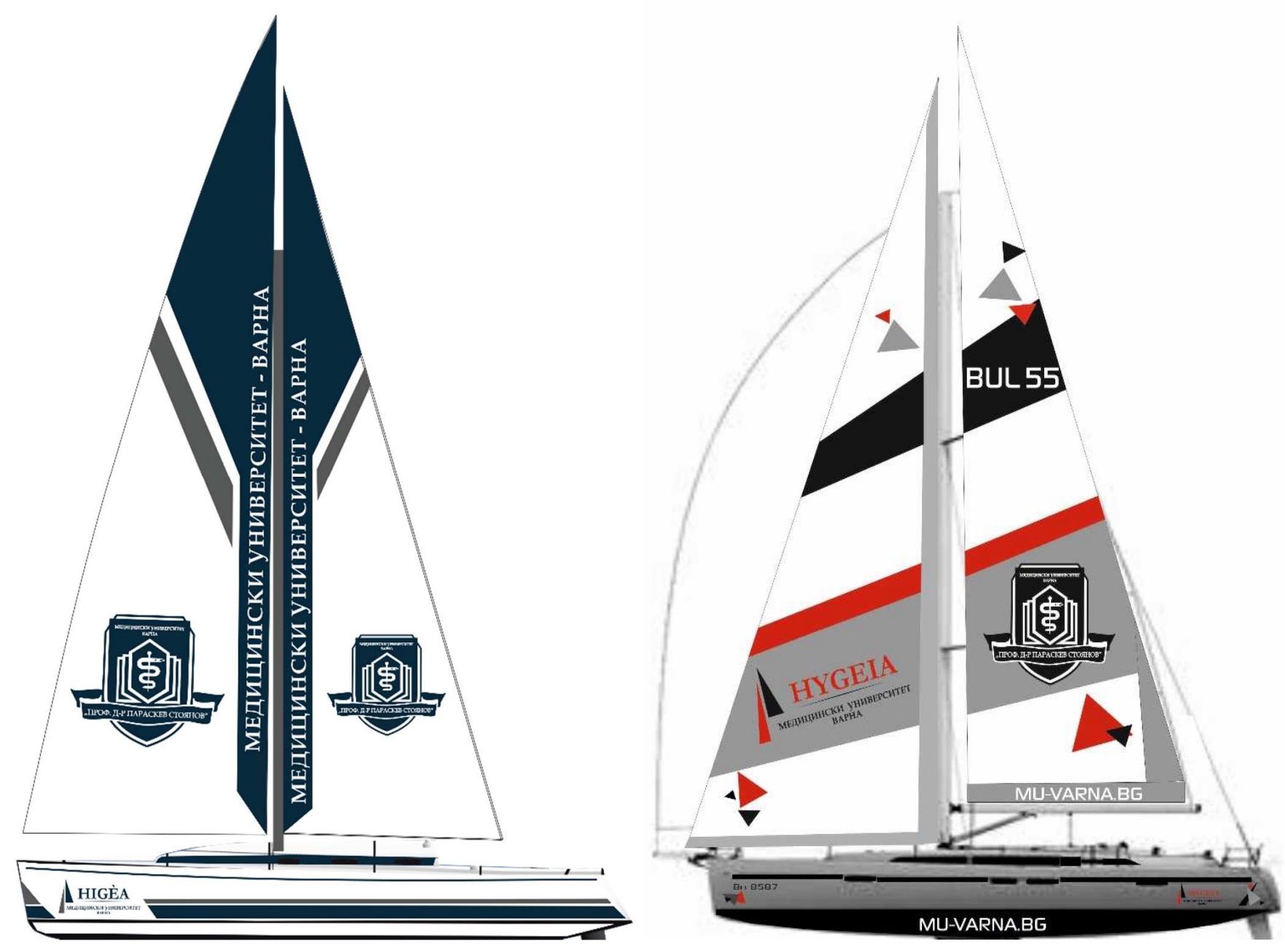

Fig. 5.Variant 3 and $4 .^{5}$

In Variant 5 a much more multilayer and specific appearance was achieved. The color triangles led to a strong contrast of the long black and red lines at the lower end of the sails, the logos placed on a larger surface area and the registration number is quite discernible. There still exists the problem of a possible imbalance and not very good distinctive outline of the logos when the shape of the sails changes. 
Before finalizing the ideas for graphic details on the sailing boat, however, the functionalvisual characteristics of the materials used in branding (Fig. 6) and their role in the overall impression and impact of the project had to be specified. Special 3M folia had been used for the elements on the hull. Their characteristics include durability in extreme external conditions and the possibility for various colour combinations.
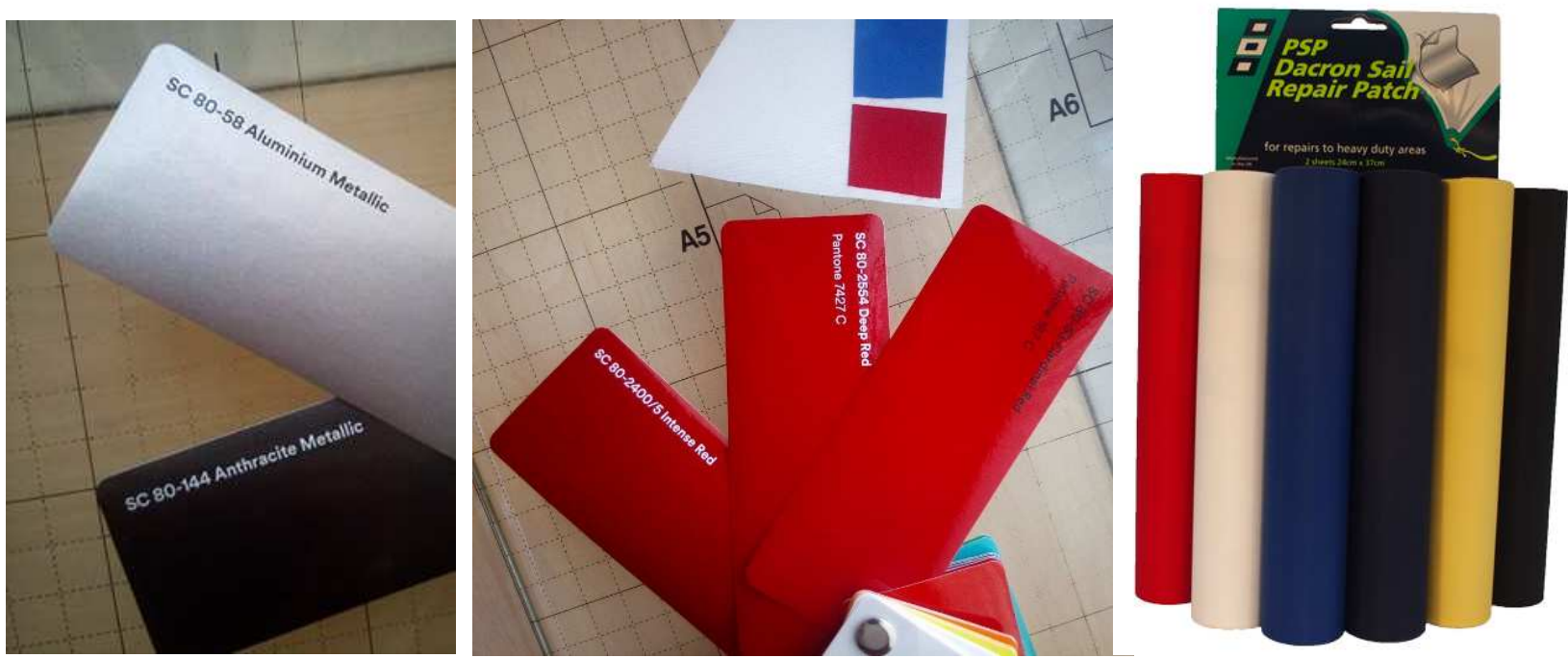

Fig. 6. Materials used in branding. ${ }^{6}$

It was established that the necessity for strength of the elements on the sails limited the choice of materials to a great extent. The most appropriate material was considered to be "insignia" advertising or promotional material. It endures the constant changes in weather conditions (Мархай, 1988) and they add to the durability of the sail (Fig. 7). The material used though can lead to unnecessary thickening / at places, where the appearance needs arranging in layers/ and is offered in a limited choice of colours which additionally influenced the choice of the final brand variant. As a result of the combination and specificity of requirements on the one hand and the technical characteristics of the materials used, the necessary appearance of the sailing boat was attained.
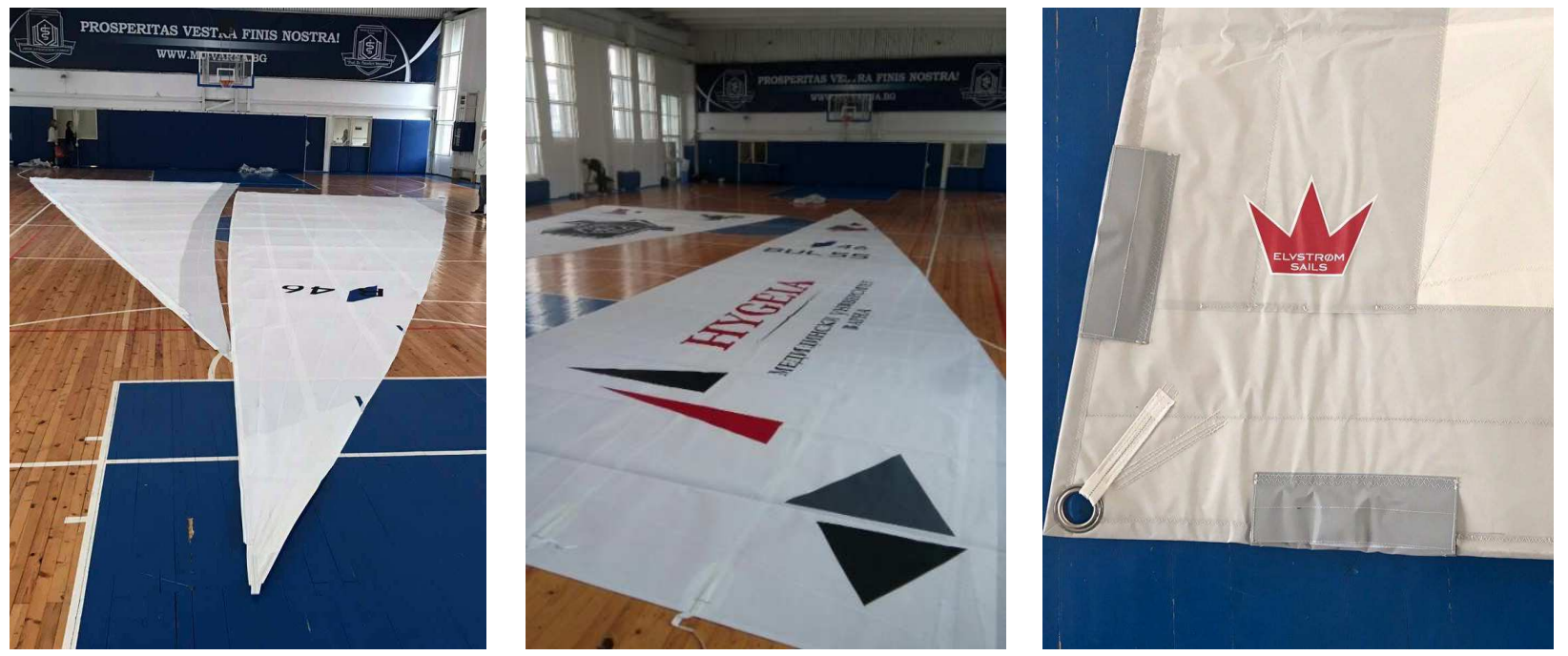

Fig. 7.Part of Variant 6 conclusive (final). ${ }^{7}$

${ }^{6}$ Materials used in branding ${ }^{6}$

${ }^{7}$ Part of Variant 6 conclusive (final). ${ }^{7}$ Personal archive. 
There were some triangle elements left that made the appearance of the sailboat effective and full of contrast in the basic colours black and red, adding a complementary grey colour for balance. The sailboat's logo which is characterized by a larger amount of text, is exposed on the main sail and is positioned next to the main mast in such a way that it does not allow deformation of the image as a result of the wind force. The logo of MU-Varna is written in black, white combination was positioned in an appropriate place which allows optimal stretching and spreading across a larger surface area. The reduction of additional details helped towards a greater distinction of the elements and solved the problem with the weight of the sails. The lines and triangles on the hull and the sails of the sailboat were placed with the aim to increase the sports appearance of the yacht, while the overall subdued shades and tones that brought light were projected in such a way that they enhanced the elegant and dynamic design. (Fig. 8).
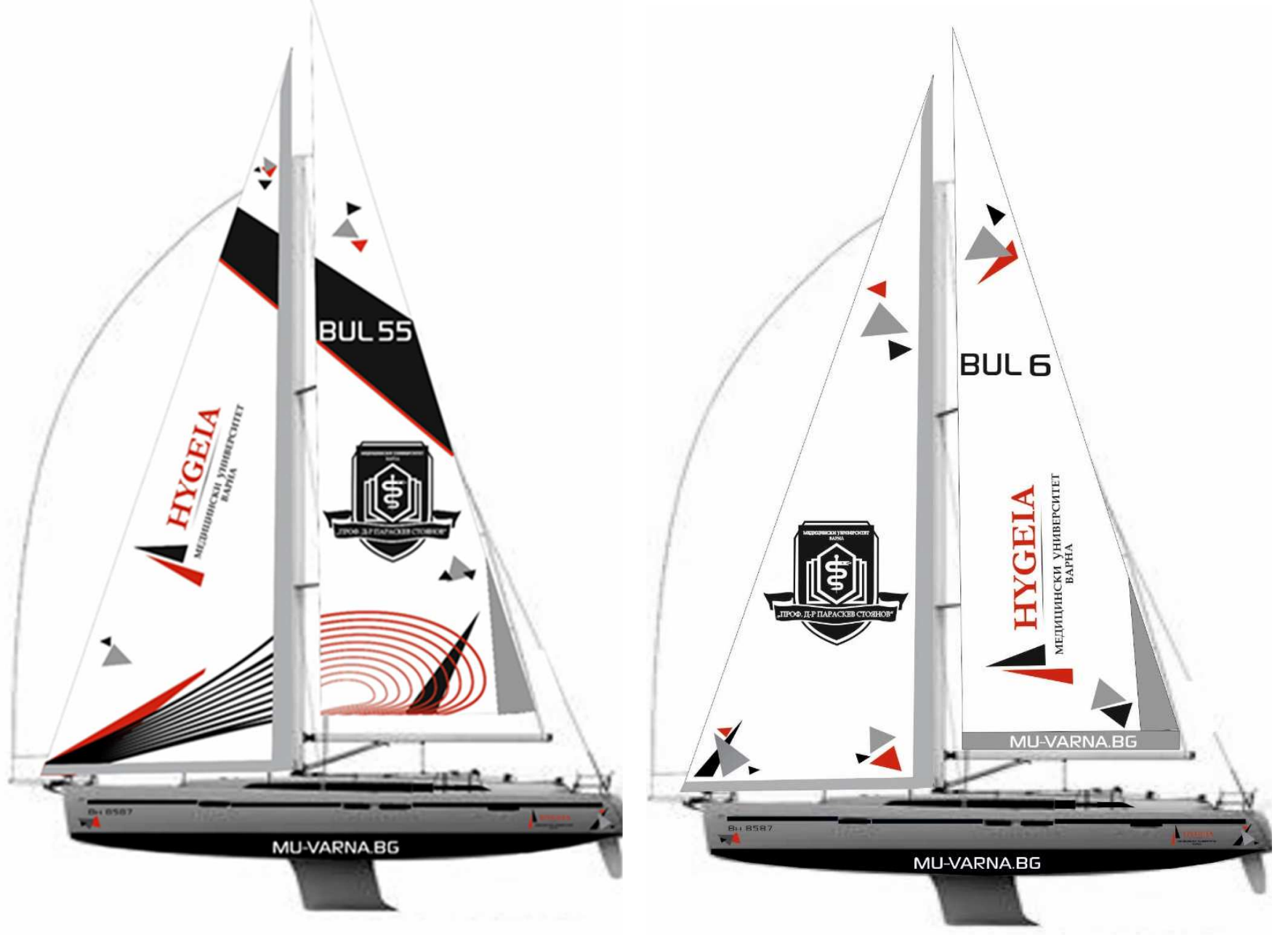

Fig. 8.Variant 5 and 6 / General appearance of the final variant „Hygeia“ $/ .8$

The chosen concept for a design was reproduced and the style of the appearance adapted to the other two motorboats "Panacea" и "Talassa" (Fig. 9). Because of the different shape and size of the boats, a direct repetition of the artwork was impossible. Following the general line of style, an effect of "belonging to a family" (Макуейд, 2007) was achieved and the design played its role of a unifying common factor. High-quality $3 \mathrm{M}$ folia in black, red and grey were used in both sailing boats. These $3 \mathrm{M}$ folia emphasize their sports and dynamic appearance.

${ }^{8}$ Variant 5 and 6 / General appearance of the final variant „Hygeia“ $/ .{ }^{8}$ Personal archive. 

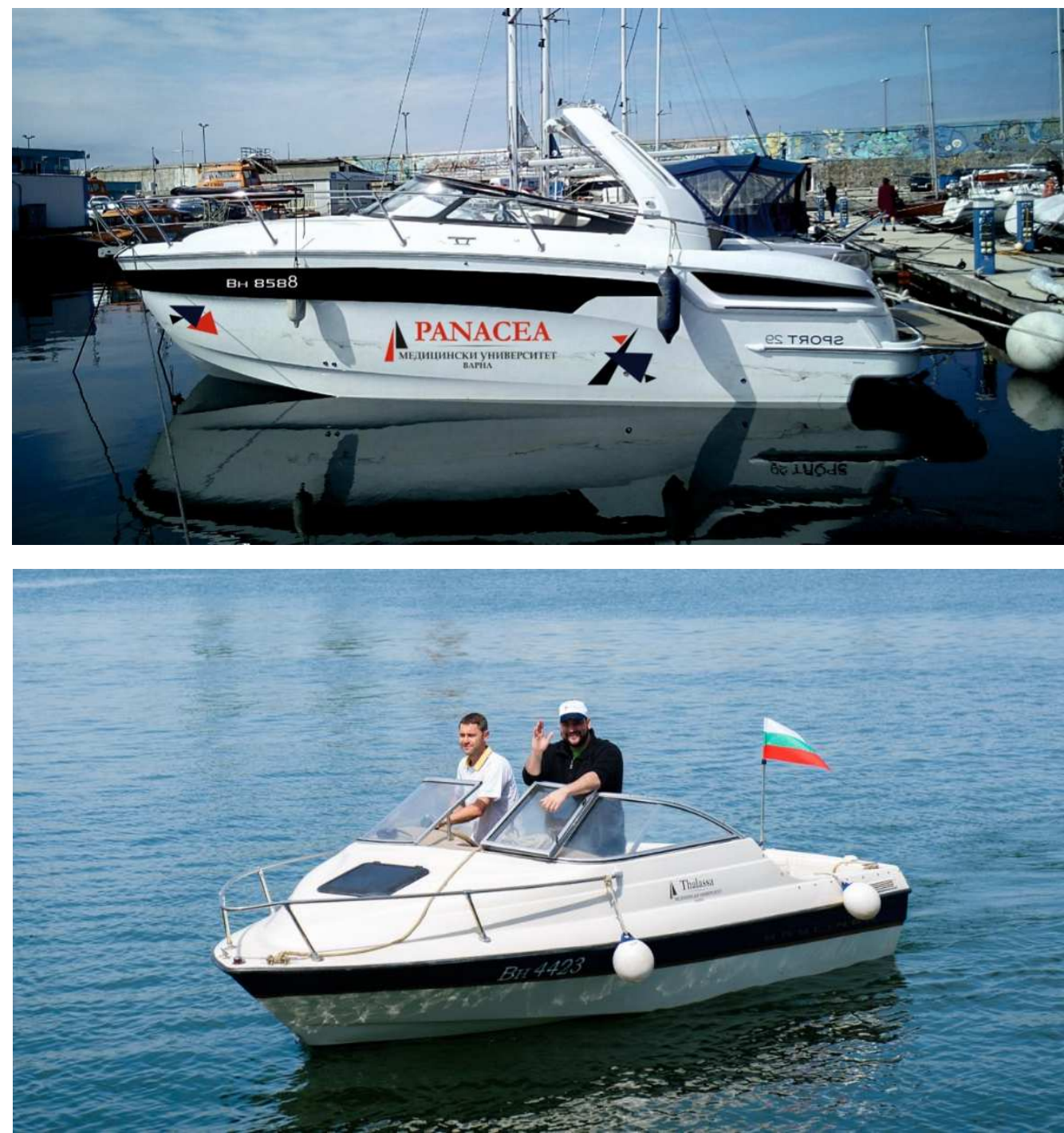

Fig.9.The overall appearance of Panacea and Talassa motorboats. ${ }^{9}$

\section{Conclusion}

By way of conclusion it should be pointed out that carefully and accurately worked out principles that build the contemporary public relations are an important part of the general communication policy of the university. They play a significant role in establishing, sustaining, enhancing and making a given university image popular. Universities themselves being a kind of cultural and spiritual phenomenon, an intellectual community and an institution simultaneously, tend to build their own specific system of symbols that contain academic signs and traditions through a well-designed graphic PR strategy. In the course of time they turn into an inalienable and irrevocable part of the national culture. The well-structured PR communication strategy becomes more and more important in the context of continuously growing competition between the universities.

Attention should be focused on contemporary criteria for creating an efficient visual concept and criteria which optimally meet the specific requirements and needs of universities. Thus, a university image is created that is full of dignity and integrity, an image of an institution with long history and traditions. Every new, innovative and unconventional opportunity for popularizing, advertising and enhancing the university prestige should be used and developed.

The major conclusion that should be drawn is that the contemporary strategy for design of academic regalia needs to be coordinated with the existing traditions in the socio-cultural mentality

${ }^{9}$ The overall appearance of Panacea and Talassa motorboats. ${ }^{9}$ 
and mind-set on a national level with a visionary thinking and orientation to the future so that quality and long-lasting products of design maybe guaranteed. In this sense, the designer style in creating and decorating the sports sailing boats of MU-Varna is an example of introducing an overall and allencompassing PR strategy. This leads to the conclusion that academic communities of both state and private universities in Bulgaria, should agree on the idea of standardization in the sphere of graphic, visual and ritual academic symbols. A designer goal in this respect could be the creation and implementation of a clear-cut and straightforward methodology for planning academic symbols on the basis of a profound theoretical and practical analysis of the principles of the design of academic regalia in an existing university.

\section{References}

Лольр, Б. (2006). Дизайн, предпечат и печат-официално ръководство. ИК" СофтПрес", София.

Мархай, Ч. (1988).Теория на плаването под ветрила. Ветроходство, хидродинамика, аеродинамика, Военно издателство;

Макуейд, Д. (2007). Професионален дизайн на бизнес материали. Софтпрес.

Тачева, Хр. (2016). Ролята на графичния дизайн в академичния pr, "Первой международной научной конференции "Дизайн и художественное творчество: теория, методика и практика" Санкт- Петербург, Русия, р. 88-95

Tacheva, H. V. (2017). Features of representative design for academic needs-development of conceptual models when designing symbols and regalia. Annual Journal of Technical University of Varna, Bulgaria, 1(1), 67-76. https://doi.org/10.29114/ajtuv.vol1.iss1.35

Тачев, М. (2015). Изкуството на камуфажния дизайн, Стено р.57-58 р.65

\section{Online sources (visited 06.2018)}

http://solutions.3m.com/wps/portal/3M/bg_BG/3MWindowFilm/WindowFilm/Products/ http://www.geology.bas.bg/plancton/links_bg.html

http://vetrohodstvo.com/za-nas/lodki/

http://www.bulsaf.bg/?lang=bg_BG

http://www.sailing.org/

https://en.wikipedia.org/wiki/Sailing

https://www.obekti.bg/chovek/edin-narchnik-za-perfektnite-kombinacii-ot-cvetove 